\title{
ANÁLISE DAS PERCEPÇÕES DE ESTUDANTES SOBRE O PROJETO DE EXTENSÃO ROBESC DURANTE A PANDEMIA DE COVID-19
}

DOI: 10.37702/2175-957X.COBENGE.2021.3500

Fernanda Souza Coimbra Machado - fecoimbra96@gmail.com

Centro Federal de Educação Tecnológica de Minas Gerais CEFET MG Avenida Maria Fernandes de Barros 389

36770-238 - Cataguases - MG

Elvis Martins Nicolau - elvismarttins@hotmail.com

Centro Federal de Educação Tecnológica de Minas Gerais CEFET MG Rua: José Américo Ribeiro 19

36771-710 - Cataguases - MG

Mariana da Silva Almeida - lemarianaalmeida@gmail.com

Centro Federal de Educação Tecnológica de Minas Gerais CEFETMG

Rua José Camilo Ferreira 194

36707-128 - Leopoldina - MG

João Flávio de Toledo Arruda - jflaviota@hotmail.com

Centro Federal de Educação Tecnológica de Minas Gerais CEFET MG Avenida Getúlio Vargas 215

36700-216 - Leopoldina - MG

LINDOLPHO OLIVEIRA DE ARAUJO JUNIOR - lindolph@gmail.com CENTRO FEDERAL DE EDUCAÇÃO TECNOLÓGICA DE MINAS GERAIS RUA JOSÉ PERES 558

36700-000 - LEOPOLDINA - MG

Resumo: Com a chegada da pandemia do novo COVID-19, foram necessárias drásticas mudanças na vida de todos. Vários setores foram impactados. As universidades também foram afetadas, fazendo com que muitas atividades fossem para o remoto, isto é, virtual. Um dos principais desafios encontrados foram os projetos de extensão, pois estes visam levar conhecimentos adquiridos dentro das universidades para a comunidade externa. Entretanto, com as medidas de isolamento social, que almejam o bem-estar de todos, essa atividade tornou-se complexa. A Instituição CEFET-MG tradicionalmente tem um projeto de extensão 
presencial que ensina robótica para alunos do ensino fundamental Il e ensino médio, o qual foi modificado neste período de pandemia para o formato virtual. Após o projeto, foi feita uma pesquisa para saber a percepção do público alvo e se os objetivos intrínsecos do projeto foram atingidos. Com a análise do questionário foi possível ver o público objetivado, o qual apresentou grande satisfação com este e acreditam que tal recurso pode impactar a sociedade positivamente além disso, indicaria o projeto para outras pessoas.

Palavras-chave: Projeto de Extensão. Robótica Escolar. Pesquisa. Ensino Remoto. ROBESC. 


\section{ANÁLISE DAS PERCEPÇÕES DE ESTUDANTES SOBRE O PROJETO DE EXTENSÃO ROBESC DURANTE A PANDEMIA DE COVID-19}

\section{INTRODUÇÃO}

No ano de 2020, como forma de combate à disseminação do novo coronavírus, escolas e universidades brasileiras, públicas e particulares, interromperam suas atividades presenciais. Quase 56 milhões de estudantes, dos ensinos básico e superior, foram afetados pela paralisação (CHAGAS, 2021). Este cenário fez com que as Instituições de ensino do Brasil e do mundo buscassem novas ferramentas e metodologias para o cumprimento de suas atividades de forma remota (HODGES et al., 2020).

Com a publicação da portaria nํ343 do Ministério da Educação (MEC), em março de 2020, as instituições de ensino superior foram autorizadas a manter suas atividades de modo online. Não somente as disciplinas foram adaptadas ao novo formato, mas, também, projetos de pesquisa, ensino e extensão, que estavam previstos para 2020, como no caso do ROBESC.

O ROBESC (Robótica Escolar) é um projeto de extensão criado em 2012, no CEFETMG, Campus Leopoldina, que tem como objetivo atrair alunos para as áreas de ciência e tecnologia através do ensino da robótica, além de estimular o trabalho em equipe. O público alvo do projeto são alunos do Ensino Fundamental II e Ensino Médio de escolas públicas de Leopoldina e região. Nas fases I, II e III, o projeto atuava presencialmente, ofertando minicursos e promovendo competições entre os alunos participantes. Para as fases IV e V, que estavam previstas para o primeiro e segundo semestre de 2020, respectivamente, a dinâmica seria a mesma. Entretanto, com a chegada da pandemia de COVID-19, foi necessária uma mudança no formato de execução do projeto.

Este artigo mostra um estudo sobre o projeto de extensão ROBESC, fases IV e V, apresentando como a ação foi conduzida durante a pandemia: desde a escolha das ferramentas de ensino até a execução dos minicursos. A seção 2 aborda como eram realizadas as primeiras fases do projeto, anteriores à pandemia de COVID-19. Na seção 3 é apresentada a metodologia adotada para o ensino da robótica durante o isolamento social. A seção 4 mostra os resultados obtidos pelo projeto através de uma pesquisa feita com os participantes após o término dos minicursos. E, por último, na seção 5, são tratadas as conclusões finais sobre o ROBESC.

\section{HISTÓRICO ROBESC}

O nome ROBESC vem de Robótica Escolar. É um projeto de extensão que teve início no Programa de Educação Tutorial (PET) do curso de Engenharia de Controle e Automação do Centro Federal de Educação Tecnológica de Minas Gerais (CEFET-MG), Campus Leopoldina. Este possui 5 fases concluídas, ou seja, 5 ciclos de atividades de extensão completos.

O projeto teve origem no ano de 2012, quando ocorreu a fase I. No ano de 2020 foi finalizada a fase V. No decorrer dos anos, Leopoldina e cidades no entorno foram participantes, tendo como foco principal alunos do ensino fundamental II e ensino médio.

Ele é dividido em objetivo principal e objetivos específicos. O objetivo principal é o ensino de conceitos básicos de fluxograma, programação e atividades práticas. Tem por objetivos específicos: despertar nos alunos o interesse em pesquisa e desenvolvimento tecnológico, sustentabilidade e despertar para a possibilidade de seguir carreira na área de ciência e tecnologia; Realizar a inserção tecnológica dos alunos, proporcionando aos 
mesmos a possibilidade de aprendizado na área de robótica; Complementação do aprendizado com conceitos de aplicação de informática e lógica estruturada; Despertar nos alunos o interesse pela área de controle e automação e computação e, também, produzir um canal permanente de comunicação com os participantes e escolas como forma de aumentar a inserção do CEFET-MG na região.

Além dos objetivos citados anteriormente, o projeto almeja englobar a metas para os Objetivos de Desenvolvimento Sustentável (ODS), tais como: ODS 4 - Educação de Qualidade, ODS 5 - Igualdade de Gênero, ODS 17 - Parcerias e Meios de Implementação (Objetivos de Desenvolvimento Sustentável, sem data), dessa forma, tornando-se um agente ativo na construção de um futuro melhor. Em adição, o projeto também anseia por impactar nos discentes voluntários e bolsistas de forma a contribuir para formação cidadã através do desenvolvimento de habilidades sociais dos mesmos.

Nas 3 fases iniciais do projeto foram feitas atividades presenciais usando o kit LEGO Mindstorms como principal ferramenta de ensino e aprendizado por fornecer um ambiente de programação amigável para crianças, totalmente visual e utilizando-se de movimentos de "arrastar-e-soltar". O kit é composto por peças plásticas de encaixar, um controlador principal, motores, rodas, polias e correntes, sensores de luminosidade, cores, temperatura, ultrassônico e outros (Lego Mindstorms, 2021).

Para a fase IV, que vinha sendo planejada antes da pandemia do COVID-19, foi planejada uma abordagem diferente das anteriores. Para esta fase foi programado o uso de Arduino juntamente com o kit chassi carro 2WD utilizando sensores infravermelho e ultrassônico. Contudo, com a chegada da pandemia, foi necessário rever o planejamento.

\section{METODOLOGIA}

No início de 2020, antes do surgimento da pandemia de COVID-19, a equipe do projeto ROBESC estava preparando suas atividades para a fase IV. O planejamento contava com cursos presenciais de Arduino, que abordavam conteúdos de lógica de programação e eletrônica básica. Um carrinho robótico, composto de um circuito eletrônico e um placa Arduino, foi desenvolvido pelos integrantes do projeto, para que pudesse ser programado pelos alunos, com o objetivo de aplicar os conhecimentos adquiridos durante os minicursos.

O Arduino é uma plataforma eletrônica de código aberto baseada em hardware e software fáceis e intuitivos de usar. As placas do Arduino são microcontroladores monoprogramáveis que podem receber informações de sensores, processar essas informações e atuar em saídas como LEDs (Light Emitting Diode) ou motores (Arduino, 2021).

A interrupção das atividades escolares de forma presencial fez com que a programação inicial do projeto tivesse que se adaptar à nova realidade. O ROBESC necessitou direcionar as atividades de toda equipe para o formato online, através de reuniões pela plataforma RNP (Rede Nacional de Ensino e Pesquisa), e utilizando mídias sociais para divulgação do projeto, que foram de suma importância. Foi ofertado pelo projeto cursos online de Arduino e Lego que envolvem lógica de programação, eletrônica básica e os princípios de funcionamento dos sensores e atuadores. As duas plataformas gratuitas, utilizadas nos minicursos ofertados, foram a plataforma Tinkercad, para o curso de Arduino, e a plataforma Open Roberta, para o curso de Lego.

O projeto de extensão em 2020 teve a participação de 11 estudantes dos cursos de Engenharia de Controle e Automação e Engenharia de Computação e de 4 professores coordenadores do CEFET-MG unidade de Leopoldina, diante do cenário de isolamento social, os integrantes do projeto distribuíram igualmente as atividades a serem realizadas. 
Foram criadas 3 áreas dentro do projeto: marketing, responsável pela divulgação do ROBESC nas redes sociais; logística, encarregada dos testes e escolha da plataforma de videoconferência e de divulgar o projeto nas escolas da região; documentação, responsável pela confecção das atas e formulários de inscrição. Além disso, foram adotadas reuniões ocorridas semanalmente por meio de videoconferência, todas registradas em ata assinada por todos os participantes, a respeito das tomadas de decisões. No decorrer das reuniões, foi necessário definir e avaliar as ementas para elaborar o material didático, com o intuito de direcionar os ministrantes e facilitar o aprendizado dos alunos. O material era formado por uma apresentação em slides abordando conteúdos teóricos e passo-a-passo das práticas.

Os encontros foram previstos para ocorrerem 1 vez por semana, sendo realizados 9 encontros de 1 hora de duração cada, baseando-se no modelo de aulas remotas adotado pelo CEFET - MG, pois foi considerado ideal para transmitir o conteúdo e sanar as eventuais dúvidas. Para não comprometer a qualidade do aprendizado e dos conteúdos ofertados nos cursos, foi definido um limite de 20 alunos por turma com 2 ministrantes e demais membros no suporte para registro de presença e solução de problemas técnicos.

Os cursos do projeto de extensão ROBESC, Arduino e Lego, foram todos ministrados pela plataforma de reuniões e videochamadas RNP. Para melhor desenvolver a criatividade e raciocínio lógico dos alunos, a equipe usou a metodologia de aulas expositivas dialogadas, que consiste em apresentar os conceitos teóricos e listar os componentes eletrônicos necessários para realização das práticas, abrindo espaço para questionamentos e discussões (SA et al., 2017).

A prioridade era a independência dos alunos nas práticas, contudo, havendo dificuldades, a equipe auxiliava nas dúvidas e no processo de montagem das práticas. Para maximizar a autonomia no processo de aprendizagem, foram propostos desafios para serem feitos em casa baseados no conteúdo da aula. Assim, no encontro seguinte, a equipe poderia verificar se os alunos que conseguiram fazer o que foi proposto e compreender as aulas.

Ao final de cada encontro, foram enviados para os alunos um formulário de avaliação das aulas, anônimo e opcional, com algumas perguntas referentes à qualidade do material, áudio, vídeo e plataforma de videoconferência, com o objetivo de aprimorar a experiência dos alunos durante o curso.

Os dois minicursos desenvolvidos foram conduzidos de forma similar em relação a carga horária e objetivos por aula, distinguindo apenas a plataforma utilizada. Durante as aulas os ministrantes compartilhavam suas telas explicando os conteúdos e direcionando as atividades práticas. O roteiro e procedimentos utilizados serão especificados nos tópicos a seguir.

\subsection{Minicurso Arduino}

O minicurso de Arduino teve 3 turmas. Para turma 1 ocorreu às segundas feiras às 11:00h, entre os dias 14 de setembro e 16 de novembro e para as turmas 2 e 3 ocorreu às quartas feiras 19:00h, entre os dias 16 de setembro e 11 de novembro. A ementa do minicurso Arduino envolveu lógica de programação, noções básicas de eletrônica, noções básicas do funcionamento dos sensores e atuadores e, por fim, simulações relacionadas ao Arduino realizadas na plataforma Tinkercad. Essa ementa foi sugerida para que qualquer pessoa pudesse participar, mesmo não tendo nenhum conhecimento nas áreas abordadas. Foram utilizadas as plataformas Portugol Web Studio - é um ambiente para aprender a programar, voltado para os iniciantes em programação que falam o idioma português (Portugol Studio, 2021) e Tinkercad - plataforma de ferramentas 3D e de simulações de circuitos eletrônicos que ajudam as pessoas a criar, pensar e fazer, desenvolvida pela 
Autodesk (Tinkercad, 2021). O motivo das escolhas das plataformas foi devido a facilidade de se aprender a programar no idioma português, bem como melhor compreender a lógica de programação e a possibilidade de simulação dos circuitos desenvolvidos com a placa de prototipagem Arduino. Os conteúdos práticos abordados são mostrados na Tabela 1.

Tabela 1 - Práticas e conteúdos abordados no curso de Arduino.

\begin{tabular}{c|c}
\hline Práticas & Conteúdos abordados \\
\hline Piscar LED & Saída digital \\
\hline Botão controlando LED & Entrada e saída digital \\
\hline Simulando um semáforo & Entrada digital \\
\hline Acionando buzzer com botão & Entrada e saída digital \\
\hline Leitura de sensor de luz LDR & Entrada e escrita analógica \\
\hline Acionamento de um motor Micro Servo & Entrada e escrita analógica \\
\hline Fonte: Autoria própria &
\end{tabular}

\subsection{Minicurso LEGO}

O minicurso Lego teve 1 turma e ocorreu às segundas feiras às 19:00h, entre os dias 14 de setembro e 16 de novembro. A ementa do minicurso de Lego envolveu noções básicas de eletrônica, noções básicas do funcionamento dos sensores e atuadores e por fim simulações realizadas no ambiente de simulação Lego Open Roberta - a plataforma Open Roberta foi desenvolvida para ensinar crianças e adolescentes a programarem kits robóticos e adentrar no mundo da ciência da computação (OPEN ROBERTA, 2021). A Tabela 2 mostra os conteúdos práticos abordados durante o curso.

Tabela 2 - Práticas e conteúdos abordados no curso de LEGO.

\begin{tabular}{c|c}
\hline Práticas & Conteúdos abordados \\
\hline Robô que desenha & Como se utiliza o sensor de toque \\
\hline Robô que desvia obstáculos & Como se utiliza o sensor ultrassônico \\
\hline Robô seguidor de linha & Como se utiliza o sensor de cor \\
\hline Robô seguidor de linha com obstáculos & Sensor de cor e sensor ultrassônico \\
\hline Seguidor de linha usando sensor de luz & Como se utiliza sensor de luz (Light Sensor) \\
\hline Fonte: Autoria própria &
\end{tabular}

\section{PESQUISA}

Em versões anteriores do ROBESC, a equipe era composta por um número pequeno de integrantes. Para as fases IV e $\mathrm{V}$, a equipe teve seu número elevado e, portanto, a expectativa era abranger uma quantidade de participantes maior dentro do público alvo. Para isso, foi trabalhado fortemente nas mídias sociais para a divulgação do projeto, bem como no contato com as escolas locais.

Ao final do prazo de inscrições foi possível obter 63 inscritos, um número inferior do que o esperado. Haja vista que o projeto ocorreria virtualmente, não foi feita nenhuma restrição dos participantes, ou seja, qualquer pessoa poderia participar, mesmo não sendo o foco do projeto. De acordo com as inscrições, 33,3\% (21 estudantes) eram do ensino fundamental II e $15,9 \%$ do ensino médio (10 estudantes). Veja a Figura 1. 
Figura 1 - Escolaridade dos participantes

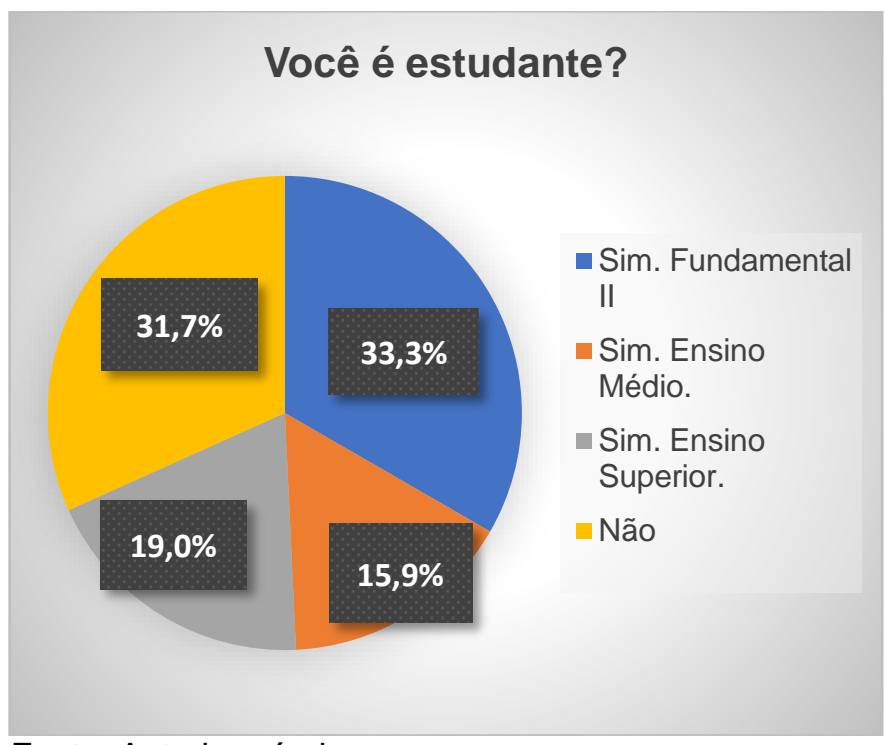

Fonte: Autoria própria

De acordo com a Figura 2 é possível ver que, dentre os participantes que eram do público alvo, houve uma preferência pelo curso de Arduino. O curso de Lego, utilizando a plataforma Open Roberta, obteve $22,6 \%$ (7 estudantes) do público do ensino fundamental II e médio, sendo que, o curso de Arduino englobou 77,4\% (24 estudantes).

Figura 2 - Preferência de curso do público alvo

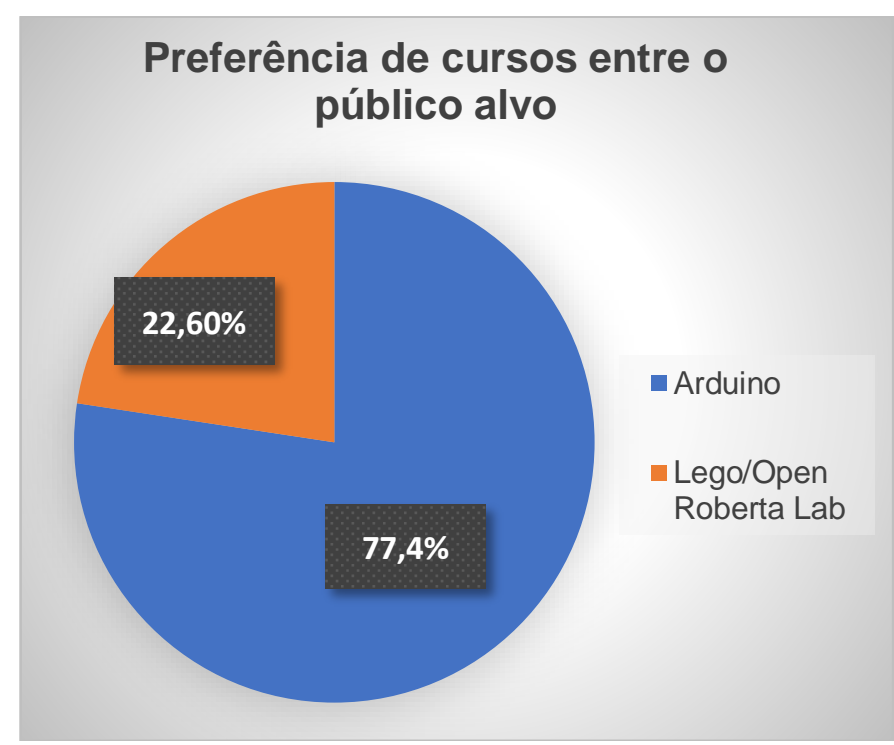

Fonte: Autoria própria

A Figura 3 mostra a relação dos participantes inscritos que faziam parte do público alvo. Destes, 67,7\% (21 estudantes) eram do ensino fundamental II e 32,3\% (10 estudantes) do ensino médio. 
Figura 3 - Relação de participantes do público alvo

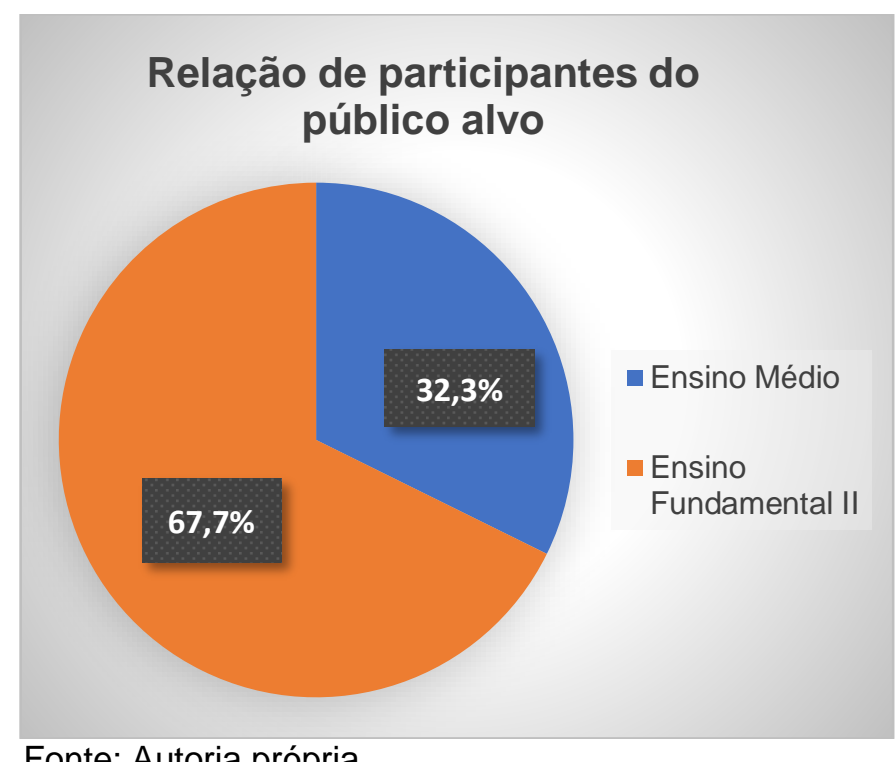

Fonte: Autoria própria

Ao final das atividades de extensão foi possível notar algumas desistências, pois 41 estudantes, sendo 21 do ensino fundamental II e médio, terminaram todas as atividades. Com isso, uma pesquisa foi feita, via formulário eletrônico, para saber a opinião de todos os participantes sobre o projeto. A amostragem obtida foi de 23 respostas, o que representa $56,1 \%$ da população total de alunos certificados. Este artigo objetiva analisar, exclusivamente, as respostas dos estudantes de fundamental II e médio.

A Figura 4 mostra os níveis de escolaridade para os participantes que concluíram os cursos e se dispuseram a responder a pesquisa. Tanto o ensino fundamental II como o médio tiveram a mesma porcentagem de $17,4 \%$ de respostas, ou seja, 4 respostas de cada, totalizando 8.

Figura 4 - Níveis de escolaridade dos participantes que se dispuseram a responder a pesquisa

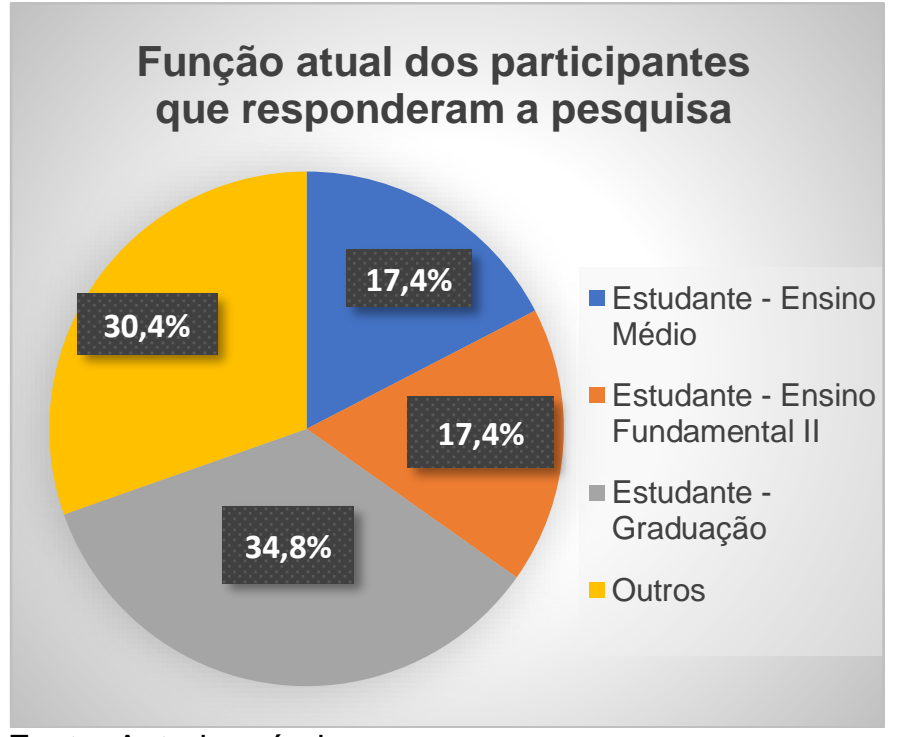

Fonte: Autoria própria 
O questionário foi sucinto, contudo, abordando pontos cruciais correlatos com os objetivos do projeto. Após a pesquisa foi possível identificar que: todos os participantes conheciam a Instituição CEFET-MG, porém, nem todos conheciam os cursos fornecidos e/ou como ingressar; Quase todos dos participantes do público alvo que se inscreveram e finalizaram os cursos pelo desejo de aprender mais sobre robótica; O principal receio deles era não entender o conteúdo.

Além disso, foi possível analisar a própria percepção dos estudantes com relação à absorção do conteúdo transmitido. Analisando a Figura 5 é possível ver que a maioria dos estudantes julga que absorveu entre $40 \%$ a $60 \%$ ou $80 \%$ a $100 \%$ do conteúdo.

Figura 5 - Relação da absorção do conteúdo transmitido

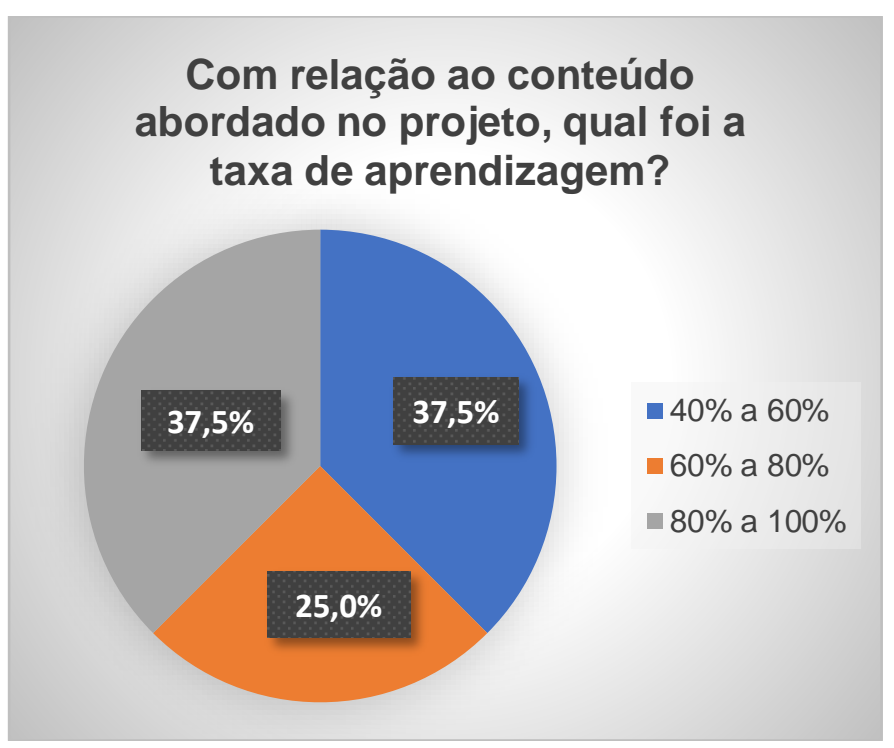

Fonte: Autoria própria

Foram feitas também outras duas perguntas: "Quanto você acha que seu raciocínio lógico melhorou após o projeto?"; "Quanto você acha que sua concentração melhorou após o projeto?". As respostas se encontram, respectivamente, nas Figuras 6 e 7. 
Figura 6 - Autoavaliação dos estudantes

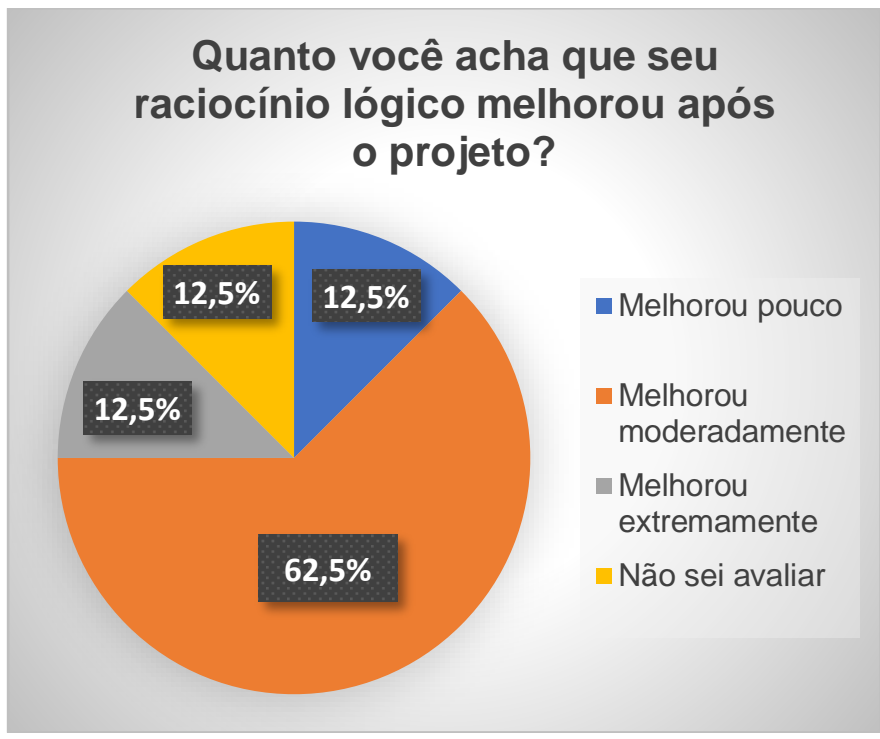

Fonte: Autoria própria

Figura 7 - Autoavaliação dos estudantes

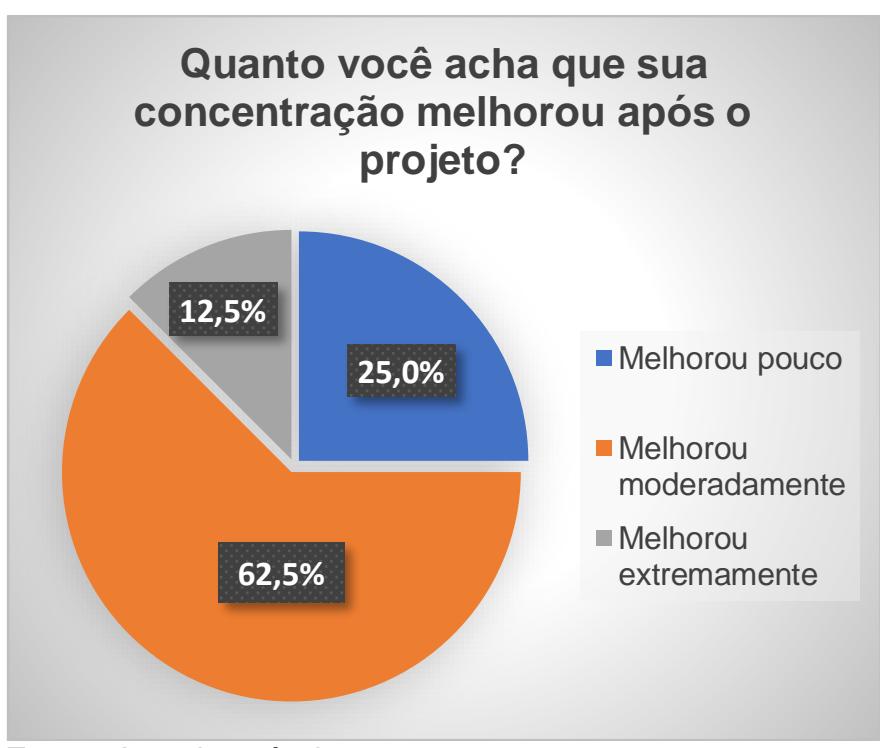

Fonte: Autoria própria

Notou-se, também, que alguns participantes mostraram interesse em ingressar na Instituição após os cursos, dessa forma, sendo um indicativo de que um dos objetivos do projeto pode ter sido cumprido.

Foi de suma importância saber se, na percepção dos participantes, o projeto impacta positivamente a sociedade. A figura 8 mostra que a maioria acredita que sim. Finalmente, a Figura 9 mostra que a parte majoritária dos alunos indicariam o ROBESC a outras pessoas. 
Figura 8 - Percepção do impacto do projeto pelos participantes

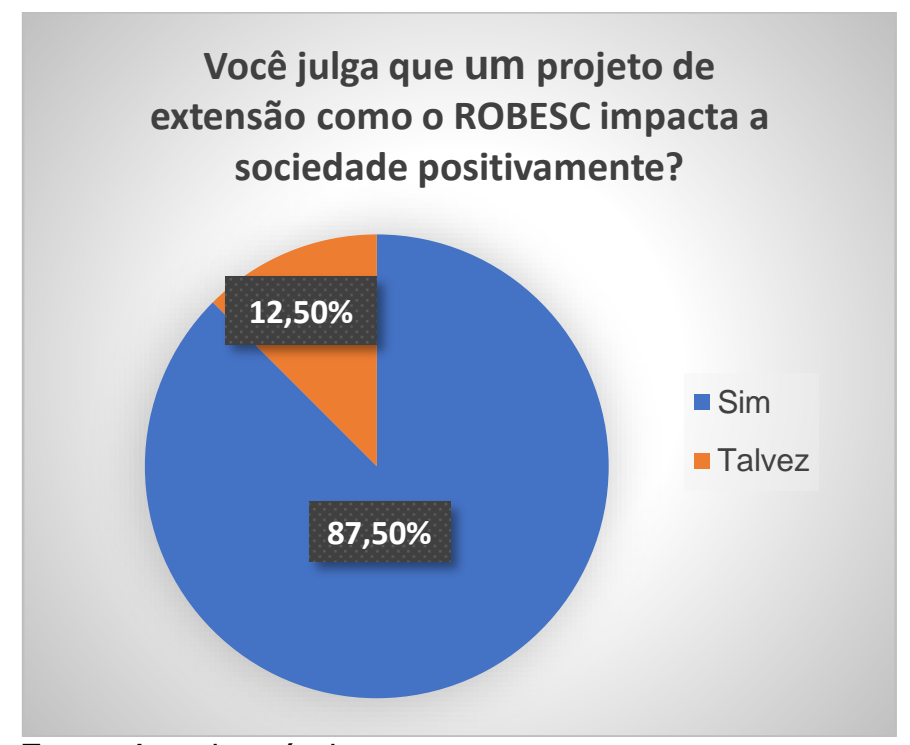

Fonte: Autoria própria

Figura 9 - Alunos que indicariam o ROBESC

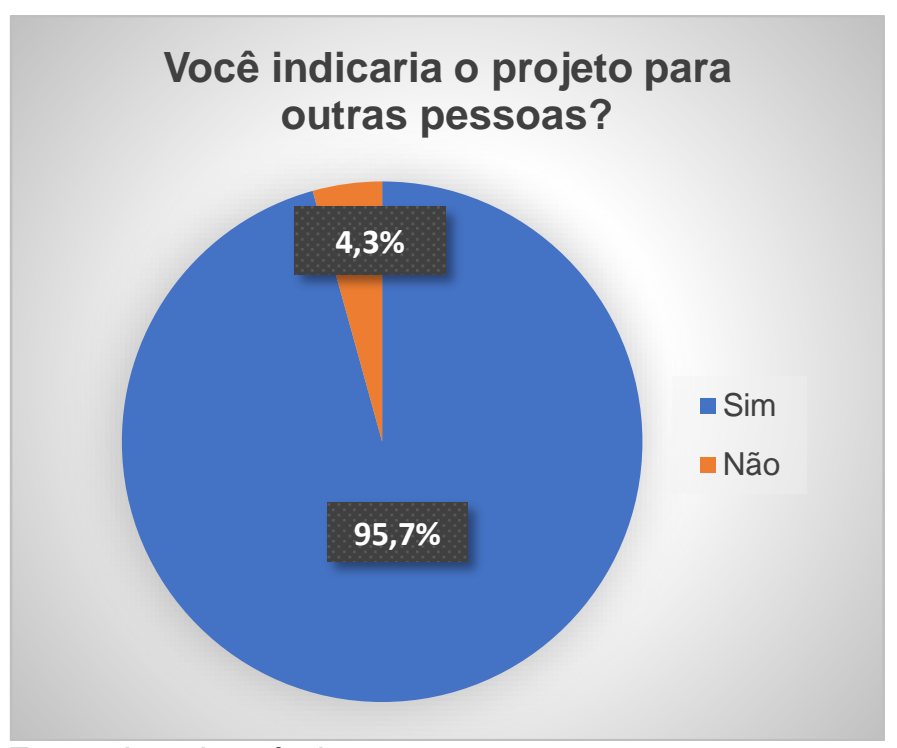

Fonte: Autoria própria

\section{CONCLUSÃO}

Este artigo objetivou mostrar os resultados obtidos em um projeto de extensão que devido a pandemia e de forma a atender as medidas de isolamento social, foi necessário acontecer virtualmente.

Foi visto que mesmo esperando um público maior e trabalhando intensamente na divulgação do projeto nas redes sociais, não foi possível alcançar o número esperado. Sendo difícil especular o porquê do ocorrido.

Contudo, foi alcançado somente uma parte do público alvo esperado, sendo que uma parcela razoável finalizou totalmente os cursos oferecidos.

Pode-se concluir também que inovar é um excelente meio de contornar problemas, tendo em vista que um projeto que é tradicionalmente oferecido presencialmente pode ser modificado para o virtual, conseguindo alcançar os objetivos requeridos, desenvolvendo 0 
raciocínio lógico e despertando o interesse dos participantes nas áreas de exatas e tecnologia.

Por fim, através das respostas obtidas, teve-se uma ideia do real impacto do projeto na vida dos participantes, pois, alguns relataram melhorias em determinadas áreas, sentiram-se motivados a ingressar em Instituição de ensino superior, bem como desejariam que outras pessoas participassem. Pode-se concluir que o projeto vem atendendo seus objetivos intrínsecos.

\section{Agradecimentos}

Os autores agradecem ao FNDE, MEC/PET/SESu e CEFET-MG pelo apoio.

\section{REFERÊNCIAS}

ARDUINO.

What

is

Arduino?

Disponível

em:

https://www.arduino.cc/en/Guide/Introduction. Acesso em: 22 abr. 2021.

CHAGAS, E. Data Senado: quase 20 milhões de alunos deixaram de ter aulas durante pandemia.

Disponível

em:

https://www12.senado.leg.br/noticias/materias/2020/08/12/datasenado-quase-20-milhoesde-alunos-deixaram-de-ter-aulas-durante-

pandemia\#: : :text=DataSenado\%3A\%20quase\%2020\%20milh\%C3\%B5es\%20de\%20alun os\%20deixaram\%20de\%20ter\%20aulas\%20durante\%20pandemia,-

Elisa \%20Chagas\%20\%7C\%2012\&text=Entre\%20os\%20quase\%2056\%20milh\%C3\%B5e s,passaram\%20a\%20ter\%20aulas\%20remotas. _Acesso em: 22 abr. 2021.

HODGES, C. et al. The difference between emergency remote teaching and online learning Friday. EDUCAUSE Review, March 27, 2020. Disponível em: https://er.educause.edu/articles/2020/3/the-difference-between-emergency-remoteteaching-and-online-learning. Acesso em: 05 mai. 2021.

OPEN ROBERTA LAB. Open Roberta Wiki. Disponível em: https://jira.iais.fraunhofer.de/wiki/display/ORInfo. Acesso em: 22 abr. 2021.

PORTUGOL STUDIO. Uma ferramenta para aprender programação. Disponível em: https://portugol-webstudio.cubos.io/. Acesso em: 22 abr. 2021.

SA, ELIANE FERREIRA DE et al. As aulas de graduação em uma universidade pública federal: planejamento, estratégias didáticas e engajamento dos estudantes. Rev. Bras. Educ., Rio de Janeiro, v. 22, n. 70, p. 625-650, jul. 2017. Disponível em: http://www.scielo.br/scielo.php?script=sci arttext\&pid=S1413$24782017000300625 \&$ lng=pt\&nrm=iso . Acessos em: 29 abr. 2021.

TINKERCAD. Da mente ao projeto em minutos. Disponível em: https://www.tinkercad.com/. Acesso em: 22 abr. 2021. 


\title{
ANALYSIS OF STUDENTS' PERCEPTIONS OF THE ROBESC EXTENSION PROJECT DURING THE COVID-19 PANDEMIC
}

\begin{abstract}
With the arrival of the COVID-19 pandemic, drastic changes in everyone's lives were required. Several sectors were impacted. The universities were also affected, making many activities to become remote, it means, virtual. Extension projects were one of the main challenges encountered, as they have the purpose of bringing knowledge acquired within the universities to the external community. However, with the social isolation measures, which aim at the welfare of all, this activity has become difficult. The CEFET-MG institution traditionally has an in-person extension project that teaches robotics to students in elementary and high school, which was converted in this pandemic period to a virtual format. After the project, a research was done to know the perceptions of the target audience and if the project's intrinsic goals were reached. With the analysis of the questionnaire, it was possible to see that the target audience was very satisfied with the project and believes that it can impact society positively, and that they would also recommend the project to other people.
\end{abstract}

Keywords: Extension Project. School Robotics. Research. Remote teaching. ROBESC. 